DOI: http://dx.doi.org/10.24093/awejtls/vol1no1.12

\title{
Cooperative Principle and Inferential Chains of Interpretation: Socio-Pragmatic Approach to Language and Literature Teaching
}

\author{
Vijay Singh Thakur \\ Department of Languages and Translation \\ College of Arts and Applied Sciences \\ Dhofar University \\ Salalah, Sultanate of Oman
}

\begin{abstract}
The author strongly believes in Black's (2006) remark that Grician Maxims of conversational cooperation have a considerable degree of relevance for the processing of literary discourse on the innermost level of character-to-character interactions (p. 27). In the backdrop of this, this paper aims to demonstrate how analytical dimension of literary studies can be expanded by involving Grice's (1975) pragmatic stylistic theory of Cooperative Priciple (CP) and explores how the fictional discourses could be better understood by reconstructing inferential chains of interpretation along with various issues of inferences in the dialogic discourses of the characters from Vikram Seth's magnum opus A Suitable Boy (ASB). The CP contributes to contextualization of the text; provides interpretative possibilities that explain how we draw inferences from conversation; and hints to interpretations of how direct and indirect discourses are manipulated in literary works of fiction. The major findings of this paper suggest that the real value and richness of conversational maxims of Grice lie not in observing but in flouting them and that the major motivation for violating the requirements of these maxims are related to characters' socio-cultural concerns such as politeness, tact, social power and taboos and also to the inter-personal factors like various cross-purposes, attitudes, personal tensions, conflicts, etc. Arriving at pragmatic meanings through the maxims of $\mathrm{CP}$ involves effort and increases engagement with the text; therefore, the author strongly recommends that pragmatic stylistic analysis be frequently included as an important pedagocial activity of studying fictional discourses in the teaching of language and literature.

Key words: Conversational implicature, cooperative principle, fictional discourse, grician pragmatics, inferential chains of interpretation, inter-prersonal pragmatics, politeness strategies

Cite as: Thakur, V. S. (2017). Cooperative Principle and Inferential Chains of Interpretation: Socio-Pragmatic Approach to Language and Literature Teaching. Arab World English Journal for Translation \& Literary Studies, 1(1). DOI: http://dx.doi.org/10.24093/awejtls/vol1no1.12
\end{abstract}




\section{Introduction}

To use Blackmore's (2010) words, the study of discourse takes us beyond the study of the sentence. However, we are not always taken to the same place. This happenes because we are taken beyond and away from the notion of structure altogether to the notion of discourse as social behavior which must be studied in terms of its function (p. 100). It is a common knowledge that the use of language for communication is basically a social phenomenon. Being so, most of its sanction tends to be conventional. The most common convention of communication is that speakers and listeners try to cooperate with one another in order to communicate accurately and efficiently. They cooperate, for example, on the simple mechanics of speech. Speakers talk in audible voices, use languages they believe their listeners know, and adhere to the phonology, syntax, and semantics of those languages. Just as important, however, are the conventions speakers and listeners observe in what is said and how it is expressed. Put concisely, speakers try to be informative, truthful, relevant, and clear and listeners interpret what they say on the assumption that they are trying to live up to these ideals. As Grice (1975) puts it, speakers and listeners adhere to the Cooperative Priciple (CP). The CP consists in four more specific maxims which imply communicative decisions in the four major areas of relation, quality, quantity, and manner and their significances are conveyed through these maxims as precepts to speakers in the form of how they should contribute to a conversation. It is easy to see how communication can break down when speakers do not adhere to these maxims. That is why people normally observe Grice's (1975) general principle of conversation: "Make your conversational contribution such as is required, at the stage at which it occurs, by the accepted purpose or direction of the talk exchange in which you are engaged" (p. 46). Incidentally, the real values of character utterances in a fictional discourse cannot be arrived at merely through an understanding of their lexical and syntactic structure; hence, to use Thakur's (2015) argument, pragmatic interpretative strategies need to be involved and used (p. 61).

However, to use Labov \& Fanshel's (1977) view about dyadic interaction, conversation is not a chain of utterances, but rather a matrix of utterances and actions bound together by a web of understandings and reactions (p. 29). Therefore, in Schiffrin's (1994) view, the application of $C P$ to dialogic conversations leads to a particular view of discourse and its analysis, i.e. discourse as a text whose contexts (including cognitive, social and linguistic contexts) allow the interpretation of real speaker meaning in utterances (p. 227). Furthermore, as Garfinkel (1967 in Coulthard, 1985, p. 30) remarks, it is never possible to say what one means in so many wordsspeakers require hearers to work to a greater or lesser extent to derive their message from the words uttered. So, by implication, it is also true that CP is often not obeyed and violated. There are occasions when a speaker decides to quietly and unostentatiously violate a maxim- he may lie, he may not give as much of the relevant information as he could, or he may offer utterances which are only later seen to be ambiguous. There may also be occasions when a speaker is seen to break a maxim either because he has been faced with a clash between two maxims making it impossible, for instance, for him to be as specific as he ought to be and still to say nothing for which he lacks adequate evidence, or because he has chosen to flout a maxim, that is to say he may blatantly fail to fulfill it. In such instances the conversational maxims provide a basis for the listener to infer by way of what is being conversationally implicated. Grice (1975) terms these pragmatic implications as Conversational Implicature (p. 47). Thus, a maxim can be followed in a straightforward way, a maxim can be violated because of a clash with another maxim, or a maxim can be breached or flouted. Incidentally, the violation of a maxim involves a two-stage 
process (Coulthard, 1985, p. 32)-first recognition of the apparent irrelevance, inadequacy, or inappropriateness of the utterance, which secondly triggers the subsequent inferencing. Thus, as Schiffrin (2010) remarks, the production of discourse is an interactive process that draws upon two aspects of closely related communicative knowledge, namely expressive and social: the ability to use language to display personal and social identities, to convey attitudes and perform actions, and to negotiate relationships between self and the other (p. 54).

As said in the beginning, the author's aim in this paper is to examine the pragmatic considerations of inter-personal communications in $A S B$ within the matrix of the theory of Grice's CP. This analysis will uncover how these principles of conversational cooperation provide an interpretative basis for the various referential possibilities that can be inferred and for the referring sequences that they create in ASB. The process of inferring via the Grician Pragmatics (GP) would help us to explain how textual understanding can vary. The participant assumptions about what comprises a cooperative context for communication that contributes to meaning would also help us to explicate in the novel what critics refer to as meanings between or behind the lines.

The Gricean principles or maxims apply variably to different contexts of language use and in variable degrees rather than in an all-or-nothing way. Incidentally, a similar view reflects in the two quotations of Voltaire that Vikram Seth has purposefully included (particularly in the context of the very bulky volume of ASB) just before beginning the story. The two quotations, 'The superfluous, that very necessary thing....', and 'The secret of being a bore is to say everything' clearly refer to necessarily saying more and less (respectively, p. vii) than is required. Seth, via these two quotations of Voltaire, refers to the possibilities and scope of deliberate violations of Grecian maxims of cooperation in his novel under study.

The approach that GP offers to discourse analysis is based in a set of general principles about rationally-oriented communicative conduct that tells speakers and hearers how to organize and use information offered in a text, along with background knowledge of the world (including knowledge of the immediate social context), to convey (and understand) more than what is saidput simply, to communicate. However, the analytic focus in this paper will be not only on the observance and violation of the maxims but also on the reason(s) why the characters in the novel followed or flouted them. As the principles of conversational cooperation introduce communicative values into the study of language- the values that are operative in society (Krishnaswamy, et al, 1992, p. 107), it is needless to say that the issues of social considerations along with personal motives and inter-personal relationships will be considered as factors affecting conversational behaviour of the participants in the story.To put simply, what Grice does through his pragmatic model of $\mathrm{CP}$ is to suggest ways in which we may be guided towards interpretation.

Let us begin the analysis of CP in ASB by examining the conversational considerations of quantity in it.

\section{Maxim of Quantity}

The maxim of quantity refers to the suggestion of making conversational contribution as informative as is required for the current purposes of the exchange. Thus, it restricts from saying 
too much or too little. Consequently, the quantity maxim leads hearers to search for the amount of information in a text or description. Many a times the quantity in discourse is influenced by the considerations of quality maxim in being true or untrue.

Let us examine the organization of the amount of information in some pieces of dialogic discourse from the novel.

\section{Example One}

Mrs. Rupa Mehra: Who is he? (demanded Mrs. Rupa Mehra.) Come here. Come here at once.

Lata: Lata looked at Savita. (Savita nodded.) Just a friend (said Lata, approaching her mother). (p. 181)

\section{Analysis}

The important point about the conversational maxims, as Leech and Short (1981) comment, is that unlike rules (e.g. grammatical rules) they are often violated (p. 295). The breach of the maxim of quantity can be seen in this example. Mrs. Rupa Mehra, in the context of her recent knowledge about her daughter (Lata) having an affair with some boy, questions her: 'Who is he?' Lata answers, 'Just a friend'. Let us examine her answer in terms of the considerations of the quantity maxim.

The maxim of quantity favours the provision of full information. The effect of this maxim, as Levinson (1983) remarks, is to add to most utterances a pragmatic inference to the effect that the statement presented is the strongest, or more informative, that can be made in the situation (p. 106). Lata's answer failed in this respect to lead her mother to believe so. It can be seen from the context of the ongoing conversation between the mother and daughter that Mrs. Rupa Mehra is worried and angry about Lata's relationship with the boy in question. Her concern is motivated by the social reason of pre-marital affairs of romance being looked down upon in society. Such an image of girls proves to be highly controversial and therefore disadvantageous in the matters of their prospective matrimonial alliance as the marriages in Indian socio-cultural set-up are generally arranged marriages. Naturally, she would like to know everything about the boy in question in response to her question, for example his name, his family, his caste and religion, etc. which are important factors that influence the marriage alliances. But Lata's answer- 'Just a friend'- proves to be, to use Schifffrin's (1994) phrase, referentially opaque (p. 200) as it neither refers to any specific person nor provides any definite information about him. Consequently, it entails further questioning like 'What's his name?', 'What is he- Kabir Lal, Kabir Mehra- or what?' which is evident in the text of the whole discourse unit (p. 181) in the novel. Thus, Lata's answer provides less information and violates the maxim of quantity.

Since the answer was quantitatively weak it could not satisfy Mrs. Rupa Mehra's illocutionary goal. It could not lead her to find its relevance to the text and context of her question. In this way the strongest and more informative statement involves the statement that can be relevantly made. Such implicit appeals to the maxim of relevance have prompted Wilson and Sperber (1981) to claim that the maxim of relevance in fact subsumes the other maxims. There is another aspect to the violation of quantity in this example. Lata's relationship with Kabir was beyond normal limits of friendship as has been indicated time and again in the novel. 
In such a situation, her answer- 'Just a friend'- self-evidently becomes untrue and also sounds qualitatively spurious. Thus, it is the weak quantity of the answer that is leading it to disturb the features of the other maxims of quality and relevance in the conversation.

The motivation for Lata's flouting of almost the whole range of $\mathrm{CP}$, by way of her oblique answer, lies in interpersonal factors which are at odds here with the principle of cooperation. The factors of socio-familial attitude towards a pre-marital relationship of romance and that too between a Hindu girl and a Muslim boy of 1950s and the resultant personal tension and conflict compel her to be tactful in avoiding the actual facts. It is also influenced, on the other hand, by the socially and psychologically-oriented application of a pragmatic principle of being polite and avoiding confrontation with her mother, who, by Indian social norms, holds the parental authority to question and influence the personal affairs of marriage of her children and command their obedience.

\section{Example Two}

Haresh: Shall we sit down? (asked Haresh.)

Lata: Yes. Why not?

Haresh: Well, it's been such a long time since we met (said Haresh).

Lata: Don't you count the Prahapore Club? (said Lata.)

Haresh: Oh, that was for your family. You and I were hardly present.

Lata: We were all very impressed (said Lata with a smile). (Certainly, Haresh had been very much present, even if she hadn't.)

Haresh: I hoped you would be (said Haresh). But I am not sure what your elder brother thinks of all this. Is he avoiding me? This morning he spent half the time looking around for a friend of his, and now he's going out.

Lata: Oh, he's just being Arun. I'm sorry about the scene just now; that too is typical of him. But he's quite affectionate sometimes. It's just that one never knows when. You'll get used to it. (The last sentence had slipped out of its own accord. Lata was both puzzled at and displeased with herself. She did like Haresh, but she didn't want to give him any false hopes. Quickly she added:) Like all his- his colleagues.

Haresh: (But this made things worse; it sounded cruelly distancing and a bit illogical.) I hope I'm not going to become his colleague! (said Haresh smiling.)

(p. 1145)

\section{Analysis}

In this dialogic discourse, Lata- in her response to Haresh's question, 'Is he avoiding me?'- is violating the maxim of quantity providing more than what was required to answer the question. Her verbose answer, simultaneously, also breaks the manner maxim because if she had the information asked for Yes or No would have been the apt reply. Actually, her explanatory account of Arun's behaviour, which Haresh felt to be a bit odd, can be tied to Leech's (1983) theory of minimizing the expression of impolite belief (p. 81). In the background of the solidarity-oriented texture of Indian socio-cultural norms, especially in the traditional host-guest situation, where Haresh was a special guest (potential bridegroom) who felt and complained that he was being ignored by Arun (from the host's family) which was a face-threatening situation in which Lata's direct and focussed answer without any ameliorating redressal attempts would sound blunt and impolite. Her verbose explanatory response is a mitigating step in this direction. 
Due to socio-cultural considerations Lata gives politeness a higher rating than conversational cooperation and the application of CP thus becomes weak in her conversation. This suggests that the breach of CP, at a deeper level of interpretation, involves Politeness Principle (PP).

Lata's indirect and polite explanation of her brother's odd behaviour of neglecting his guest requires Haresh to account for the communicative significance it comes to have. With the basic assumption that Lata (the hearer) is actually cooperating (as there is no evidence contrary to it) some appropriate inference must be made. The opening remark 'Oh, he's just being Arun' generates the implication that he was not deliberately trying to neglect him. And, 'You'll get used to it... Like all his- his colleagues' suggests that by temperament Arun was like that and like all his colleagues Haresh would also feel normal with him. Lata's addition of 'Like all hishis colleagues' comes as a result of an afterthought motivated by a repairing strategy. She feared that her preceding utterance might imply to Haresh that somehow she has already made up her mind in favour of him in connection with her marriage. She wanted to undo it as their marriage was not yet finalized and fixed. Her conversational behaviour at this juncture is influenced by the maxim of quality (try to make your contribution that is true). So, she expressed her official distance in 'Like all his-his colleagues'. Haresh, as a clever conversationalist, was able to read this implicature and attempted to generate a counter implication with the intention of strengthening his situation and gaining some advantage by breaking the quantity norms in his remark 'I hope I am not going to become his colleague'. He intended to lead Lata to read from it that he has almost accepted Lata as his life partner; that he hopes to be accepted as a suitable match for Lata by the Mehra family; and also that Lata herself would reciprocate in the same manner, etc.

Thus we can see how both Haresh and Lata, through the manipulation of CP, progress towards their conversational goals simultaneously maintaining their host-guest relationship.

The maxim of quantity and quality frequently work in competition with one another, i.e. the amount of information speaker gives is limited by speaker's wish to avoid telling an untruth. So, we should see, in the next section, as to how the participants in $A S B$ manage their conversational behaviour in terms of the maxim of quality.

\section{Maxim of Quality}

This maxim is related with the attempts of making one's contribution that is true. Quality maxim prescribes that conversational partners should not say anything they believe to be false and also for which they lack adequate evidence. This maxim, as Leech (1983) remarks, outweighs other cooperative maxims (p. 82). Another feature of this maxim is that it works in competition with the maxim of quantity. Put concisely, the amount of information speaker gives is, in a way, limited by speaker's wish to avoid telling an untruth. For this reason, Harnish (1976) has even proposed a combined maxim of Quantity-Quality, i.e. make the strongest relevant claim justifiable by your evidence (p. 362).

What follows next is the examination of truth/falsity considerations of this maxim in some dialogic excerpts from ASB. 


\section{Example Three}

Saeeda Bai: Tanseem is not my sister (she had said as factually as possible). She is yours. Firoz: (Firoz had stared at her in horror.)

Saeeda Bai: Yes (Saeeda Bai had continued). She is my daughter, God forgive me.

Firoz: (Firoz had shaken his head.)

Saeeda Bai: And God forgive your father (she had continued). Now go in peace. I must say my prayers.

Firoz: (Firoz, speechless with disgust and torn between belief and disbelief, had left the room...) (p. 1192)

\section{Analysis}

This example is designed to be a case of deliberate, on-record adherence of $\mathrm{CP}$ and intended to convey very crucial factual information to the listener. As for the context of the text, Saeeda Bai, a courtesan, is the speaker and Firoz, the son of a big landlord Nawab of Baitar, is the recipient. Saeeda Bai has a young girl called Tanseem with her whom people know to be her sister. Saeeda Bai notices that Firoz is developing some soft feelings towards Tanseem. She fears that his soft feelings may lead to becoming their infatuation, passion, and love. With this troubling apprehension in mind she, one day, calls Firoz to her house. It is at this juncture that the clarificatory text under examination is exchanged with Firoz. The truth of the fact conveyed in Saeeda Bai's utterances can be seen in the conversation of Saeeda Bai's attendant Bibbo with Firoz later (p. 1193) and also can be guessed from the envelope of regular monthly endowment that Nawab of Baitar used to send her. (p. 1229)

Though the example being discussed here displays the adherence to all the four maxims of quantity, quality, relation and manner, the need to follow the quality maxim is at the core of Saeeda Bai's intended goal of communication and actually it is the binding force for the other maxims as conveying the truth, in a serious manner, is the crucial need of the hour. Her main concern is to convey the truth to Firoz that Tanseem is, in fact, his sister and her daughter, so that she can stop Firoz from unknowingly developing a relationship of romance with Tanseem. Needless to say that the communicative situation here is defined by a global culture as no society in the world approves of such a relationship to happen.

In order to avoid breaking the maxim of quality, Saeeda Bai uses more definite and assertive locutions in 'Tanseem is not my sister', 'She is yours', 'She is my daughter', 'God forgive me', and 'God forgive your father'. It was not difficult for Firoz to calculate the straightforward implicature (from 'God forgive me' and 'God forgive your father') that Tanseem was his sister by way of his father's sexual mistake with Saeeda Bai. The resultant perlocution of Firoz in becoming dumbfounded at the shocking news and staring at Saeeda Bai in horror is based on the standard quality implicature (Levinson, 1983, p. 105) that one believes what one asserts. This, in a way, suggests that there should be a mutual relevance between the maxim of quality and assertions as assertions help in being factual in conversations. This phenomenon reflects Grice's (1975) observation that the maxims of CP derive not from the nature of conversation per se, but from the fact that talking is "a special case of variety of purposive, indeed rational behaviour" ( $p$. 47). 


\section{Example Four}

Maan: (...Maan grabbed hold of the munshi's fat, rough stubbled neck and started shaking him wordlessly and violently, hardly mindful of the terror in the man's eyes. His own teeth were bared, and he looked terrifying.)

The munshi: (The munshi gasped and choked-his hands flew up to his neck...) Sahib! Sahib! (croaked the munshi, finding his voice at last.) Huzoor knows it was only a joke-a way of- these people- I never intended-a good woman- nothing will happen-her son, his field back- Huzoor must not think- (Tears were rolling down his cheek.)

Maan: I am going (said Maan, half to himself, half to Waris). Get me a rickshaw. (He was sure he had come within an inch of killing the man.)

The munshi: (the resilient munshi suddenly leapt forward and almost lunged at Maan's feet, touching them with his hands and his head and lying, gasping and prostrate before him.) No, no, Huzoor-please-please-do not ruin me (he wept, unmindful of his audience of underlings). It was a joke-a joke-a way of making a point-no one means such things, I swear by my father and mother.

Maan: Ruining you? (said Maan, dazed.) (pp. 641-42)

\section{Analysis}

In order to account for the real communicative significance and value of the conversational behaviour of the participants in the discourse under investigation, it is necessary-as a preliminary contextual scaffolding-to describe the power pattern that exists between them. Their utterances are highly influenced by the power principle. Maan is the son of the Revenue Minister Mahesh Kapoor who is the chief architect of the Zamindari Abolition Bill and also a close friend of Firoz, the son of Nawab of Baitar. Mahesh Kapoor and Nawab Sahib share a familial friendship. And the munshi is a traditional clerical head in the Baitar Estate. Thus, there is a huge gap of social status between Maan and the munshi. The speech event begins when Maan witnesses (unobserved) the munshi's bad, cruel, and inhuman treatment with a poor and helpless village woman who was called there to be warned and threatened against her son's offence of trying to get his tenancy on the village records. This makes Maan very angry and violent and he manhandles the munshi in the presence of his underlings. The munshi became terrified of the whole situation. He visualized that the news of threatening a woman against their tenancy right would not increase Mahesh Kapoor's tenderness towards the Baitar Estate of Nawab and that what might happen if the Nawab Sahib himself, who liked to imagine that an estate could be run painlessly and benevolently, came to hear of his threats to the old woman. He also knew that Maan was Firoz's close friend who was volatile and his father was fond of him and sometimes listened to him. Thus, the situation was critical and against him. So, the munshi-through his utterances of total surrender and pleadings-tries to control and undo the threat of the situation.

Munshi's pleading speech is self-evidently a case of an overt violation of the truth considerations of the quality maxim. The quality maxim, as we know, suggests the speakers not to say things that they believe to be false and also that which they lack adequate evidence for. There is no evidence, either in character utterances or authorial commentary, to suggest that the munshi could justify his speech in terms of the quality maxim. Thus, both from the text and its context, it is not difficult to understand that the munshi's utterances are blatantly false and become a speech of an ostentatious flouting of the quality maxim. It being so, the munshi cannot be trying to deceive Maan, particularly in the present context of the power paradigm between 
him and Maan. Munshi's socially obligatory addressee-elevating address terms Sahib and Huzoor and his total surrender in touching Maan's feet and prostrating before him can sufficiently exhibit this. The only way in which the assumption that the munshi is cooperating can be maintained, is, if we take the munshi to mean something rather different from what he is actually saying. Searching around for a related but cooperative proposition, that munshi might be intending to convey, we arrive at his utterances to imply that it would be a great personal catastrophe for him if the matter is reported to Mahesh Kapoor, or Nawab Sahib or Firoz and that Maan should forget and forgive him of his offence. Munshi's implicature in violating the quality maxim here does not require particular contextual conditions to unfold this message. Maan's conducive reply in a declarative question 'Ruining you?' suggests that, by way of standard or generalized implicature (Levinson, 1983, p. 104), he has read the munshi's message and his expectation leads him to infer his response in favour of his plea. Quirk, et al (1985) remark that declarative questions are conducive and resemble tag questions with a rising tone in that they invite hearer's verification (p. 814). Munshi's verification of Maan's conducive question may easily lead him to read the message as-"Do you think I shall do that-ruining a weak and helpless person?'

Thus, it is a cooperative and socially motivated conversation where the munshi, in his surrendering and submissive perlocutionary response to Maan's behaviour, has adopted the assumed goal of socially powerful Maan who wanted to punish and teach him a lesson for his socially unjust behaviour of humiliating a poor and helpless woman.

The discussion of the maxim of quantity and quality in the preceding sections leads the discussion to the examination of the relevance maxim. In the following section the operation of this maxim in some talk exchanges from ASB is investigated.

\section{Maxim of Relation}

Maxim of relation is concerned with making the contribution relevant to the aims of the ongoing conversation. Relevance maxim refers to a special kind of informativeness which is related to the relevance of an utterance to its speech situation. The utterance will be relevant, as Leech (1983) remarks, to the speech situation if it can be interpreted as contributing to the conversational goal(s) which may include both social goals (e.g. observing politeness) and personal goals (such as finding one's book) (p.94).

Maxim of relation leads hearers to use information in a certain way, i.e. to find its relevance to the rest of the text and to the context in which it is situated. To use Blackmore's (2010) argument, relevance is a property of a mentally represented interpretation of the evidence a communicator provides for the thought(s) she or he intends to communicate, and is defined in terms of a function of the effects this interpretation has on the hearer's overall representation of the world and the effort that is needed for its derivation (p. 114).

Sperber and Wilson (1986), who built on Grice's work, claim that the maxim involving relevance subsumes all the other maxims and the relevance is more important than the other maxims in that whatever maxim is originally broken, the relevance maxim is always used in inferring the consequent conversational implicature. 
In the following couple of pages the author will examine the functioning of this super maxim of relevance in certain dialogues from ASB.

\section{Example Five}

Sandeep Lahiri: WHOSE wife are you? (Sandeep Lahiri was Presiding Officer at one of the many polling stations in Salimpur.)

A woman voter: How can I take his name? (asked the burqa-clad woman in a shocked whisper.) It is written on that slip of paper which I gave you before you left the room just now. (p. 1244)

\section{Analysis}

The woman voter, on the surface, has put another question as response to Sandeep Lahiri's question. He, as a Presiding Officer, wanted to check her husband's name before allowing her to cast her vote. Though her question is a rhetorical question for which she has no intention of eliciting answer, it doesn't complete the incomplete proposition of Sandeep Lahiri's question. The woman, as a cooperative listener, should have supplied her husband's name as answer. Thus, her rhetorical question appears to be unconnected, insincere and irrelevant. In a way it violates the maxim of quality. On the surface level her rhetorical question violates the maxim of relation as it differs from the required answer that the Presiding Officer has asked for. But her violation of relevance is not clandestine. By implication she wants to convey something more. She expects the Presiding Officer to realize that she has adhered to the principle of conversational cooperation and so her contribution is relevant to what he has just asked. And if he takes it to be relevant, which he actually does, he will see that there is some restrictive hesitation on her part for uttering her husband's name. And what follows after her question is an indirect answer to Sandeep Lahiri's question, i.e. he can find out her husband's name from the voter's slip that she gave him some time ago. The intentions of the woman are in no way face-threatening as her decision to flout the maxim of relevance ostentatiously is motivated by the social norm which restricts the village women from uttering their husband's name as a mark of deference. This practice still prevails in villages. Instead, the village women, in their routine social interactions, address their husbands as the father of their child/children. They use, for example, phrases like Munnu ke Papa, i.e. the father of Munnu where Munnu is the pet name of the child. Her rhetorical question draws Sandeep Lahiri's attention toward this social norm. Thus, it reflects upon Leech's (1983) observation that listener's conversational goal also includes a social goal of observing the cultural norms (p. 94).

The operation of the relevance maxim in the talk exchange discussed above cannot be satisfactorily explained without due consideration of the cultural norm that regulates the woman's answer as it accounts for the gap between the overt sense and the pragmatic force of her response. On the surface her rhetorical question counts as anomalous since it does not advance a well-formed answer to the Presiding Officer's question but it does become relevant if it is understood as an explanation of why she cannot answer his question.

\section{Example Six}

Mr. Sahgal: Shall I buy you a sari?

Lata: No-no-

Mr. Sahgal: Georgette drapes better than chiffon, don't you think?

Lataa: (Lata gave no answer.) 
Mr. Sahgal: Recently Ajanta pallus have become the craze. The motifs are so-so- imaginative-I saw one with a paisley design, another with a lotus-(Mr. Sahgal smiled.) And now with these short cholis the women show their bare waists at the back as well. Do you think you are a bad girl?

Lata: A bad girl? (repeated Lata.)

Mr. Sahgal: At dinner you said you were a bad girl (explained her uncle in a kindly measured way). I don't think you are. I think you are a lipstick girl. Are you a lipstick girl?

Lata: (With sick horror Lata remembered that he had asked her the same question when they were sitting together in his car five years ago...) A lipstick girl? (Lata had asked puzzled. At that time, she had believed that women who wore lipstick, like those who smoked, were bold and modern and probably beyond the pale.) I don't think so (she had said).

Mr. Sahgal: Do you know what a lipstick girl is? (Mr. Sahgal had asked with a slow smirk on his face.)

Lata: Someone who uses lipstick? (Lata had said.)

Mr. Sahgal: On her lips? (asked her uncle slowly.)

Lata: Yes, on her lips.

Mr. Sahgal: No, not on her lips, not on her lips-that is what is known as a lipstick girl. (Mr. Sahgal shook his head gently from side to side and smiled, as if enjoying a joke, while looking straight into her bewildered eyes.)

Lata: (... Lata had felt almost ill. Later, she had blamed herself for misunderstanding what her uncle had said. She had never mentioned the incident to her mother or to anyone, and had forgotten it. Now it came back to her and she stared at him.)

Mr. Sahgal: I know you are a lipstick girl. Do you want some lipstick? (said Mr. Sahgal, moving forward along the bed.)

Lata: No-(cried Lata.) I don't-Mausaji-please stop this-

Mr. Sahgal: It is so hot-I must take off this dressing-gown.

Lata: No! (Lata wanted to shout, but found she couldn't.) Don't, Please, Mausaji. I-I'll shoutmy mother is a light sleeper-go away-Ma-Ma-

Mr. Sahgal: (Mr. Sahgal's mouth opened. He said nothing for a moment. Then he sighed. He looked very tired again.) I thought you were an intelligent girl (he said in a disappointed voice... He got up... in a forgiving voice, he said :) I know that deep down you are a good girl. Sleep well. God bless you.

Lata: No! (Lata almost shouted.) (pp. 591-92)

\section{Analysis}

The conversation of this excerpt from the novel begins with Mr. Sahgal's offer of buying a sari for Lata. Lata declines his offer. Then her maternal uncle, Mr. Sahgal tries to persuade her in 'Georgette drapes better than chiffon, don't you think?' Lata breaks the maxim of manner and gives no answer. Up to this the exchanges are relevant in the form of questions and relevant Yes or No answers. But the onward direction of the conversation suddenly shifts from its theme and a disruption in the continuity of the topic comes in, which makes Mr. Sahgal's contributions inappropriate and more difficult for the hearer (Lata) to follow.

The sudden deviation from his 'Shall I buy you a sari?' to the strange utterances like 'Do you think you are a bad girl?', 'I think you are a lipstick girl?', and 'Do you want some lipstick?' 
make Mr. Sahgal's contribution irrelevant as it doesn't seem to expand on the initial topic of offer and sounds quite unconnected to its theme.

Mr. Sahgal's violation of the relevance maxim is highly oblique but calculable. Taking into account his behaviour in the past as a background, the seductive connotation of his indirect images, and his non-verbal behaviour during the conversation, it is not difficult for both the hearer and the readers to decipher his illocutionary intentions. His whole speech reflects his act of verbal seduction aimed at leading Lata to sexual activities. Mr. Sahgal's implicature, resulting from the violation of the relevance maxim, is to give hints to Lata that refer to his sexual motives.

The Indian socio-cultural norms restrict free use of overt expressions related to sex, especially when interlocutors belong to different sexes, and it is regarded as immoral and improper. Motivated by this Mr. Sahgal's conversational contribution entails repeated use of sexual hints in the expressions like 'Bare waists of women at the back as well', 'a lipstick girl using lipstick not on her lips', 'It's so hot- I must take off this dressing gown', etc. As a result, his contribution breaks the relevance criterion of conversational cooperativeness.

This piece of conversation between Mr. Sahgal and Lata is a good example which suggests and displays as to how the interpretation of indirect illocutions heavily depend on the maxim of relation. This dependence manifests itself in what Leech (1980) calls a hinting strategy (pp. 11214). This conversation is also a good example in support of an argument that dramatic interaction frequently demonstrates a complex ecology of social and cognitive relations, i.e. communication in the drama and novel often proceeds in ways that do not follow the normal sequential, reciprocal model of interaction between the speaker and the hearer.

It is now time to discuss the last maxim of conversational cooperativeness-the maxim of manner. The next section deals with the examination of this maxim in certain pieces of dialogue from the novel under study.

\section{Maxim of Manner}

Grice's maxim of manner is rooted in being perspicuous and clear. It is concerned with avoiding obscurity, ambiguity, wordiness, and disorderliness in one's use of language.

The maxim of manner, like the maxim of relation, favours the most direct communication of one's illocutionary point, and both, for that reason mitigate the obliquity of the hinting strategy. In this way the maxim of manner supports the maxim of relation.

As Leech (1983) observes, the maxim of manner rarely figures in explanations of conversational implicature (pp. 99-100). Grice (1975) himself sees this maxim as, in some sense, less important than (e.g.) the Maxim of Quality and also as differing from the others in 'relating not... to what is said but, rather, to How what is said is to be said' (p. 46).

What follows next is the examination of manner in some inter-personal discourses from the novel under study. 


\section{Example Seven}

Raja of Marh: It is not right (he said).

The Chief Justice: (The Chief Justice leaned forwards.)

Raja of Marh: It is not right. We too love our country. Who are they? Who are they? The land(he expostulated.) (The courtroom reacted with shock and amazement. The Rajkumar stood up and took a tentative step towards his father. His father shoved him aside.)

The Chief Justice: (The Chief Justice said, rather slowly:) Your Highness, I cannot hear you. Raja of Marh: (The Raja of Marh did not believe this for one instant.) I will speak louder, Sir (he announced).

The Chief Justice: (The Chief Justice repeated:) I cannot hear you, Your Highness... (p. 702)

\section{Analysis}

Any reasonably informed participant will know that the maxims of conversational cooperativeness are normally observed in highly academic and business talks and legal language which are mostly informative, content-oriented, and factual. Departing from this view the extract under examination can be seen as a good example of the exploitation of the maxim of manner. By using an ambiguous remark to Raja of Marh (Your Highness, I cannot hear you.) the Chief Justice is violating the maxim of manner (be perspicuous: avoid ambiguity). There are two possible interpretations to this remark-one that refers to Raja of Marh's low voice which is not hearable with the implication to speak louder and the other that he should not speak directly to the court (observing procedural norms) implying that his Counsel should refer his arguments to the Court. By deviating from the norms of the manner maxim the Chief Justice intends to lead his hearer, the Raja of Marh, to the interpretation of his communicative intent that goes beyond the logical meaning of the utterance (not being able to hear his voice). In Weiser's (1975) terms the addressee is called upon to infer the relation between the utterance and the purpose (p. 649). But the dominant feature of the legal conversation being factual and content-oriented is actually blocking Raja of Marh's interpretation of this purpose which eventually leads to an oddity of the situation in the novel where conversational cooperation seems to break down resulting in an unpleasant scene in the court room when the Chief Justice had to eventually order the removal of Raja of Marh from the court.

The motivation for the Judge's deviation from the norms of the manner maxim in using an indirect and divided illocution lies in the social reasons of being polite to Raja of Marh in consideration of his social status as a former King. The preference for his whimperative (Your Highness, I cannot hear you.) over the imperative (... say it through your counsel.) or the nonoffending form over the offending form, to use Steever's (1977) argument, is an outcome of the desire to be or appear to be polite (p. 595). And in being polite one is often faced with a clash between the CP and PP so that one has to choose how far to trade off one against the other (Leech, 1983, p. 83). Thus, judging the odd and adverse conversational result of Raja of Marh's response in 'I will speak louder, Sir' the Chief Justice had to, at a later stage of conversation; revert to the factual interpretation of his intended implication in 'If you have something to say, kindly say it through your Counsel'. The conversational implicature in this exchange seems to be more relevant at author-audience level of discourse than at the character-character level thereby creating the effect of dramatic irony. This example can, thus, be used to illustrate as to how the adherence to the norms of the manner maxim can be an important pragmatic constraint on the use of language in legal settings. 


\section{Example Eight}

Prof. Mishra: I am sure you have looked through the candidates' applications and so on (said Prof. Mishra jovially).

Prof. Jaikumar: (Professor Jaikumar looked very slightly surprised.) Yes, indeed (he said).

Prof. Mishra: Well, if I may just indicate a couple of lines of thought that might smoothen the process tomorrow and make everyone's task easier- (began Professor Mishra). A sort of foretaste, as it were, of the proceedings. Merely to save time and bother. I know you have to catch the seven o'clock train tomorrow night.

Prof. Jaikumar: (Professor Jaikumar said nothing. Courtesy and propriety struggled in his breast.) Prof. Mishra: (Professor Mishra took his silence for acquiescence, and continued.)

Prof. Jaikumar: (Professor Jaikumar nodded from time to time but continued to say nothing.)

Prof. Mishra: So- (said Professor Mishra finally.)

Prof. Jaikumar: Thank you, thank you, most helpful (said Professor Jaikumar). Now I am forewarned and fore-armed for the interviews ... (p. 1269)

\section{Analysis}

The viloation of the maxim of manner can be seen in this example where Prof. Mishra and Prof. Jaikumar are discussing about the following day's interviews for the selection of a reader (i.e. Associate Professor) in the Department of English of Brahmpur University. Professor Mishra's utterances in being laboured, prolix, and indirect break the considerations of manner (be brief and avoid ambiguity and obscurity). At the surface level Prof. Mishra is seen expressing his intention of making everyone's task easier in order to save time and bother but at the underlying level his hidden intentions are different. By seeing beyond the utterances in Professor Mishra's undue hospitality, his desperation to discuss candidatures before the actual interviews, and his indirect and polite rhetoric, it was not difficult for Professor Jaikumar to read the intended implications of his verbal efforts. Prof. Mishra's illocutionary intention of influencing Professor Jaikumar to support the candidate of his choice the next day actually echoes indirectly in Prof. Jaikumar's perlocutionary response in ' Thank you, thank you, most helpful. Now I am fore-warned and fore-armed for the interviews'.

Socially obligatory indirectness and obscurity in Professor Mishra's polite mode of rhetoric is due to his deliberate attempt to camouflage his manipulative efforts of influencing the selection process in trying to gain an expedient favour from the subject expert for the interview to the advantage of a candidate of his choice. As directly asking someone for a difficult, undue, and expedient favour amounts to impolite commanding, his indirect and vague approach is strategic which reflects Patil's (1994) view that considerations of politeness force people to beat about the bush rather than saying what is on their mind as a communicative device (p.153).

Thus, this example may be a good instance of justifying Leech's (1983) claim that CP is needed but it is not sufficient as an explanation of why people are often so indirect in conveying what they mean (p. 80).

\section{Conclusion}

In this paper the author has analyzed several excerpts of dialogic discourse from $A S B$ using the theory of GP. GP is a functional approach to language, the main constructs of which are located outside of language per se in speaker meaning (speaker intention) and rational principles 
of human communication (i.e. the $\mathrm{CP}$ ). The author has examined as to how the participants in the novel manage their conversational behaviour in order to achieve their illocutionary or discoursal goals in hand at the time of talk. It is evident that sometimes the characters adhere to the specifications of Grice's four maxims of quantity, quality, relation, and manner, but often they violate them. It is clear that the value and richness of the conversational maxims lies not in observing but in flouting them as a result of which a literary artist is able to generate various aesthetically satisfying devices. The author tried to trace out the reasons for the violation of these maxims in ASB and found that the major motivation for it lies in characters' inter-personal factors such as various cross-purposes, attitude, tension, conflict, etc. and more importantly socio-cultural factors like politeness, tact, social power, and taboos, etc when they find them at odds with the principles of cooperation. This dichotomy tends to become the basis for the inference of extra meanings in fictional and dramatic dialogues. Needless to say that much of what we learn in literary discourse comes from such inferences. The extra meanings that we thus extract account for the gap between overt sense and pragmatic force (i.e. implicatures) of the utterances. These meanings help us understand the real value of character utterances and enable us to better describe various aspects in the novel or a drama in a broader perspective of personal and socio-cultural considerations of the participants in a variety of communicative situations.

A socio-pragmatic analysis of the dialogic discourses from ASB via the pragmatic model of Grice has shown us that the maxims of $\mathrm{CP}$ are not sufficient to account for the conversational complexities of the participants in all the communicative situations. Quite often the politeness strategies tend to become more important in the management of one's conversational behavioursometimes as a complementary strategy and other times as a supplementary device.

In view of the motivating reasons discussed above the author strongly recommends involving students of literature as well as language in analyzing fictional discourses using the Grician Framework of $\mathrm{CP}$ in order to not only strengthen their criticial thinking skills but also to raise their inter-persoanal pragmatic awareness.

\begin{abstract}
About the Author:
Dr. Vijay Singh Thakur is an Associate Professor of English Language and Linguistics in the Department of Languages and Translation of Dhofar University, Sultanate of Oman. He holds a doctorate degree in Applied Sociolinguistics. His main publications include: the books Discourse Analysis of a Novel: Theory and Method and Sociolinguistic Perspectives of Politeness in Communication and over 25 research papers in the fields of Applied Sociolinguistics, Pragmatic Discourse Stylistics, Cross-Cultural Pragmatics, and TESOL Pedagogy.
\end{abstract}

\title{
References
}

Black, E. (2006). Pragmatic stylistics. Edinburgh: Edinburgh University Press.

Blackmore, D. (2010). Discourse and relevance theory. In D. Shiffrin, D. Tannen, \& H. E. Hamilton (Ed.) The handbook of discourse analysis (pp. 100-118). USA, UK, Australia: Blackwell Publishing.

Coulthard, M. (1985). An introduction to discourse analysis. UK: Longman.

Grice, H. C. (1975). Logic and conversation. In P. Cole \& J. L. Morgan (eds.) Syntax and semantics 3. New York: Academic Press, 41-58.

Harnish, R. M. (1976). Logical form and implicature. In Bever, Katz, \& Langendoen, Op. cit., 


\section{3-92.}

Krishnaswamy, N., Verma, S. K., Nagarjan, \& M. (1992). Modern applied linguistics. India: Macmillan.

Labov, W. \& Fanshel, D. (1977). Therapeutic discourse: Psychotherapy as conversation. New York: Academic Press.

Leech, G. N. (1980). Language and tact. In Leech (1980), 79-117. (Originally Linguistic Agency, University of Trier, Series A, Paper 46, 1977.)

Leech, G. N. \& Short M. H. (1981). Style in fiction. London: Longman.

Leech, G. N. (1983). Principles of pragmatics. London and New York: Longman.

Levinson, S. C. (1983). Pragmatics. Cambridge: Cambridge University Press.

Patil, Z. N. (1994). Style in Indian English fiction: A study in politenes strategies. New Delhi: Prestige Publishers.

Quirk, R., Greenbaum, S., Leech, G. \& Svartvik, J. (1985). A comprehensive grammar of the English language. London and New York: Longman.

Seth, V. (1993, rep. 2001). A suitable boy. New Delhi: Penguin Books.

Schiffrin, D. (1994). Approaches to discourse. Oxford, Cambridge: Blackwell.

Shifrrin, D. (2010). Discourse markers: Language, meaning and context. In D. Shiffrin, D. Tannen, \& H. E. Hamilton (Ed.) The handbook of discourse analysis (pp. 54-75). USA, UK, Australia: Blackwell Publishing.

Sperber, D. \& Wilson, D. (1986). Relevance. Cambridge, MA: Harvard University Press.

Steever, S. B. (1977). Raising, meaning and conversational implicature. In Papers from the thirteenth regional meeting of the Chicago linguistic society, 590-602.

Thakur, V. S. (2015). Speech act approach to discourse: Socio-semantic study of Vikram Seth's A Suitable Boy. In P. Mishra \& S. K. Bardhan (Eds.) Linguistic criticism and literary studies: Theory and practice (pp. 60-102). New Delhi: Adhyayan Publishers.

Weiser, A. (1975). How not to answer a question: purposive devices in conversational strategy. In Papers from the eleventh regional meeting of the Chicago linguistic society. Chicago, 649-60.

Wilson, D. \& Sperber, D. (1981). On Grice's theory of conversation. In Werth, 1981, 155-78. 